\title{
Retraction Note to: New probabilistic models for managing user's locations in PCS networks
}

\author{
Ahmed I. Saleh ${ }^{1}$ \\ Published online: 11 August 2015 \\ (C) Springer-Verlag Wien 2015

\section{Retraction to: Computing (2013) 95:25-66 DOI 10.1007/s00607-012-0210-3}

This article published in Volume 95, Issue 1, pages 25-66, DOI 10.1007/s00607-0120210-3, has been retracted at the request of the Editor-in-Chief as it is a duplicate of a paper that has previously been published in Int J Mobile Network Design and Innovation, Volume 3, Issue 3, pages 169-190, DOI 10.1504/IJMNDI.2010.038098.

$\bowtie \quad$ Ahmed I. Saleh

aisaleh@yahoo.com

1 Department of Computer Engineering and Systems, Faculty of Engineering, Mansoura University, Mansoura, Egypt 